\title{
ARTICLE
}

\section{Building capital through bioregional planning and biosphere reserves}

\author{
David Brunckhorst* \\ UNESCO Centre for Bioregional Resource Management, Institute for Rural Futures, University of New England, \\ Armidale, New South Wales 2351, Australia
}

\begin{abstract}
The need to implement innovative approaches to sustainability is now more critical than ever. This discussion draws on parts of the puzzle that must be assembled to achieve integrated, cross-tenure and jurisdictional management of whole regions and their peoples for a sustainable future. A regional, landscape ecology approach helps us to move on from theory and historical lessons to boldly design and adaptively develop novel on-ground models. To take an entirely different approach from conventional thinking, I draw from Common Property Resource (CPR) theory and experience, together with practical experience from the Bookmark Biosphere project. The characteristics of successful enduring Common Property regimes are identified and discussed in light of critical needs to maintain and restore social and ecological capital. I then highlight the concepts and logistical objectives behind the 30-year-old UNESCO Biosphere Reserve Program, which appears to have great potential as an operational framework within which these changes can be made. The Biosphere Reserve Program is maturing through integration of cultural needs and aspirations for quality of life, while conserving natural values and ecosystem processes. In particular, progress is being made through bioregional planning and management incorporating a variety of IUCN protected area types with novel, sustainable, resource-use diversification. The novel arrangements, experience and lessons from one developing model, Bookmark Biosphere Reserve in South Australia, are described as an example. I wish to encourage more models like the Bookmark experiment to evolve through even greater creativity and engagement with public and private partners. On-ground models that demonstrate innovative alternative land use management in the rangelands or integration across the coastal-marine interface are especially needed.
\end{abstract}

KEY WORDS: Sustainability · Capital assets · UNESCO program · Biosphere reserve

\section{INTRODUCTION}

There is growing concern that the failures of natural resource management systems observed in recent years have been greater in magnitude than those observed historically. Further observation demonstrates that social breakdown, particularly in non-metropolitan areas, plagues all nations. The 'booming' economies of many nations, particularly 'developed' countries mask the continuing downward slide of the

*E-mail: dbrunckh@metz.une.edu.au majority of rural communities and their natural resource base.

Scale is a critical attribute (see Norton \& Ulanowicz 1992, Slocombe 1993). The landscape scale is the main scale of human interaction with the environment. The landscape-regional context links multiple spatial and temporal scales of biodiversity with human uses and socio-economic imperatives. Human systems for environmental management, however, tend to be more narrowly focused and sectorally based (e.g. fisheries, forestry, national parks). As Mike Scott has pointed out, preserved natural areas and other reserves or protected areas are a necessary but not sufficient solution 
for long-term sustainability. Even a comprehensive protected areas system is not a panacea for sustaining ecological diversity - most biodiversity will always be found outside the reserve system.

Society is struggling to come to grips with increasing degradation of the land, its resources and faltering ecosystems. Governments are also realising their limited resource and professional capacities, to assist social change towards a sustainable future. This is particularly the case in rural areas of developed countries that are facing increasing deterioration of natural capital and social capital. The Landcare movement in Australia has contributed to public debate and awareness of appropriate responses of government. Governments, however, tend to be seen as financial cows to be milked rather than capacity building partners. On the ground therefore, with no broader-scale social-ecological strategic links being developed, individual Landcare projects undertaken by farmer groups are, arguably, no more than band-aids on symptoms of growing landscape-scale cancers. Holistic goal setting and issues of social and ecological scales, together with collective decision-making and networked partnering have rarely been achieved through the Landcare movement. Increasingly, authoritative authors from a variety of disciplines (economics, social sciences, biological sciences etc) are also recognising the limited capacities of traditional forms of public sector organisation to deal effectively with the scale, complexity and inter-relatedness of environmental problems for longterm sustainability. This recognition challenges the ability of compartmentalised government bureaucracies to adjust to, or engage in more integrated onground models. Institutional evolution towards a culture that can encourage and partake of integrated models requires a new definition of managementreplacing the idea of control by a few people with that of negotiation and organisational learning (e.g. Shannon 1998). Hence, land and sea management requires teamwork (by partners) based on a continually evolving consensus on the direction towards sustainable integrated resource management (Brunckhorst \& Bridgewater, 1996).

Management of larger areas of land and sea in an integrated and collectively responsible manner lends itself to the application of Common Property Resource (CPR) institutions. The theory and indeed on-ground development or CPR regimes (particularly contemporary rural examples) could provide much needed models at local and broader scales. Such approaches coupled with options for multi-tenure planning and management, through the biosphere reserve program, offer opportunities for diverse and innovative responses. Successful examples (see Brunckhorst 2000) tend to have shared characteristics, including:
- they are operational in the context of landscape (or regional) scale ecological processes;

- are trans-disciplinary; cross-sectoral and crossjurisdictional;

- are built on multiple public-private capacities;

- include collective responsibility, decision-making and monitoring; and,

- can be owned and driven by local communities.

'Biosphere reserves offer such models. Rather than forming islands in a world increasingly affected by severe human impacts, they can become theatres for reconciling people and nature; They can bring knowledge of the past to the needs of the future; and, they can demonstrate how to overcome the problems of the sectoral nature of our institutions'.

('Vision from Seville', UNESCO 1995, p. 4)

It is timely to consider holistic (including social and human) resource management systems and how we might design arrangements of collectively managed wholes, which match social and ecological systems at a variety of scales (see Brunckhorst 1998, 2000, Brunckhorst \& Coop 2000). Firstly, I will differentiate 5 kinds of capital assets (after Pretty 1998) — natural, financial, social, human and physical-discussing briefly important characteristics of social and natural capital that are pertinent to holistic, sustainable land and sea use management.

I will then outline the well-documented characteristics of long enduring common property regimes (CPR) and related social institutions (Ostrom 1990). These have been adapted into an ecological framework (Berkes \& Folke 1998) and considered in terms of complex multiple use contexts and multi-functional or nested social-ecological systems (McKean 1996, 2000, Edwards \& Steins 1998, 1999). Together these elements contribute very important parts to the puzzle of designing contemporary systems and institutions for the restoration, protection and sustainable use of natural resources (as well as social and other capital).

The functions, concepts and logistics of the UNESCO Biosphere Reserve Program provide related components to the puzzle. The program also provides a valuable 'on-ground' implementation framework to achieve our goals to develop new institutional forms delivering social and ecological sustainability. The Bookmark Biosphere project in South Australia will provide a 'real-life' illustration, demonstrating many of these complimentary and synergistic elements incorporating CPR arrangements, integrated holistic resource planning and bioregional management. It shows that the 'whole' is greater than the sum of the 
parts when it comes to integrated regional planning and management of a bioregional context using biosphere reserve principles. These lessons are flexibly adaptive for transfer and application to quite different ecological and social contexts. Adoption and modification in various contexts to facilitate other novel models is necessary.

\section{CAPITAL ASSETS FOR SUSTAINABLE FUTURES}

All landscapes are dominated by human activity. Ecosystems and human activity are inextricably linked with social and ecological components closely entwined. Any delineation between them is artificial and arbitrary. Narrowly focused land use approaches that manage for one particular production purpose perform poorly in maintaining ecological and social function across the landscape systems in which they occur. These approaches fail to address multiple factors operating across broader scales necessary for sustainable processes to be built. To be sustainable and enduring land use must be multi-functional across landscapes, human communities and economies. By definition it must sustain ecological function, biodiversity, clean natural products and agricultural production at a variety of scales, as well as sustain communities, social and formal institutions, economies and markets, also at a variety of influential scales. Sustainable land use ought to contribute a restorative function to both nature and society. It produces food and other goods for farm families and markets, but it must also deliver a range of public goods. Clean air and water, healthy soils, carbon sequestration, flood protection, biodiversity habitat, landscape quality and visual amenity are the longterm outcomes of sustainable practices. In concert these elements will also contribute important functions other sectors cannot produce, such as urban to rural migration and social cohesion.

Economic systems at all levels, from farms, livelihoods, communities and national economies, rely on the value of services flowing from the total stock of 5 distinct kinds of capital-natural, social, human, physical and financial (after Hawken 1993, Gunderson et al. 1995, Costanza et al. 1997, Daily 1997, Brunckhorst 1998, 2000, Pretty 1998).

1. Natural Capital—nature's goods and services. Comprises such things as food (both farmed and wild), wood and fibre; water regulation and supply; waste assimilation, decomposition and treatment; nutrient cycling and fixation; soil formation; biological control of pests; climate regulation; wildlife habitats; storm protection and flood control; carbon sequestration; pollination; and recreation and leisure.

2. Social Capital-the cohesiveness of people in their communities (various scales). Comprises relations of trust, reciprocity and exchanges between individuals which facilitate co-operation; the bundles of common rules, norms and sanctions mutually agreed or handed down within societies; the connectedness, networks and groups which may be formal or informal, horizontal or vertical, and between individuals or organisations; and access to wider institutions of society beyond the immediate household or community.

3. Human Capital-the status of individuals. Comprises the stock of health, nutrition, education, skills and knowledge of individuals; access to services that provide these, such as schools, medical services, adult training; the ways individuals interact with technologies; and the leadership quality of individuals.

4. Physical Capital-local infrastructure. Comprises housing and other buildings; roads and bridges; energy supplies; communications; markets; and transportation.

5. Financial Capital-stocks of money and savings. Comprises access to affordable credit; pensions; welfare payments; grants and subsidies.

These 5 assets are transformed by policies, processes and institutions to give desirable outcomes, such as jobs, welfare, economic growth, clean environment, sustainable use of natural resources, better health and education, and so on. If achieved, these desirable outcomes then feed back to help build up the 5 capital assets. When core assets are built up in an unbalanced manner, undesirable externalities, such as pollution or deforestation, or increased crime or social breakdown, erode all 5 asset bases, reduce resilience and are unlikely to be enduring. Clearly, sustainable systems build up stocks of all 5 assets. They increase the total, collective, capital base over time. But unsustainable systems deplete or run down capital, spending it as if it was income, so liquidating assets and leaving less for current and future generations.

What are the benefits of social capital? Social capital facilitates co-operation because it lowers the costs of working together. People have the confidence to invest in collective activities, knowing that others will also do so. They are also less likely to engage in private actions such as resource degradation that have both 'internal' and 'external' negative impacts. These are all similar attributes to those claimed for successful CPRs.

Other benefits conferred by social capital include:

- improved access to information and services;

- risk reduction (social capital-for example, pitching in to help each other and being able to call on support from kin and neighbours);

- greater influence over policies and legislation; 
- better management of common and shared resources through group action, as well as maintaining the bioregional ecosystems which support local communities and with which local communities share an identity (and wish to share a future);

- reduced costs of conducting business including an ability to exploit economies of scale, and reduced costs or deleterious actions on other forms of capital; and

- increased ability to adaptively learn and be innovative-innovation is an increasingly critical benefit or requirement of social systems/institutions given the growing uncertainty about economies, climates, and political processes.

Non-sustainable systems have emerged because natural capital and social capital are usually undervalued. The market signals that they are only valuable when converted into something else. Some kinds of capital are easy to value. We know how much a house or a car is worth, or what our savings can buy. But what is the value of a cohesive rural community? What is an ecologically healthy, functional and productive rural area with stable, healthy human communities, with minimal crime and conflict, worth to the Nation? Perhaps, the critical issue about these capital assets is that some are private goods and some public goods. Public goods are defined as goods or services which when consumed by a group member cannot be withheld from other members of the group, or when consumed still can be consumed by other members of the group. It is hard to pin down who is at fault when they decline. They both tend to be diminished by externalities arising from the activities of individuals or institutions. Unlike conventional capital, both natural and social capital tend to be public goods and so rarely have a market value (see also discussions by Ostrom 1990, McKean 1996, 2000). The tendency is for individuals to overuse and underinvest in them. These costs generally do not accrue to the producers of the costs, but are borne by whole societies and ecosystems. But both natural and social capital can increase under certain circumstances. Part of the solution is matching, and often nesting, of ecological and social systems and appropriate scales of space and time (Brunckhorst 1998, McKean 1998, Brunckhorst \& Rollings 1999). Natural capital can be increased if regenerative technologies matched to the ecological resource base are used that give a return whilst improving the capital stock (some examples from the Bookmark project are described). Social capital is also self-reinforcing when exchanges and reciprocity increase connectedness between people, leading to greater trust, which in turn enhances collective decision-making, confidence and capacity to innovate.

\section{GOVERNING THE COMMONS AND OTHER LESSONS}

Resource crashes of recent times might reflect Hardin's 'tragedy' associated with open-access to common resources (e.g., fisheries), but also the lack of success of privatisation as a solution (Bromley 1989, Bromley 1991). Several studies of enduring, self-governing collectives managing common property resources (CPRs) reveal that, despite relatively intensive use and unpredictability of some environmental and social elements, they sustained the natural resources under management over several centuries, clearly satisfying the criterion of sustainability. Some 1000 year old Commons survive, sustainably, today. These systems are not open-access but are areas collectively used and managed 'in common' - essentially large, but private, common areas or resources managed as such. These Common property institutions have demonstrated the capacity of these collaborative systems to survive dynamic flexibility to deliver social and environmental stability.

The lessons synthesised from these resilient socialecological institutions may be valuable in the development of sustainable solutions for the ailing rural sector of our own time. An important characteristic of enduring, self governing commons is that they all face uncertain and complex environments. In contrast to the uncertainty of these environments the populations at these locations have remained stable over long periods of time. Members have shared a past and expect to share a future. Communal tenure 'promotes both general access to and optimum production from certain types of resources while enjoining on the entire community the conservation measures necessary to protect these resources from destruction' (Netting 1976, p. 145).

The fact that these social-ecological systems are found so widely, and have a track record often over a long period, suggests that they are highly adaptive and resilient and therefore capable of responding to and managing processes, functions, dynamics and changes in a fashion that contributes to ecosystem resilience. It would appear from the above discussion that the particular combination of attributes provided by these institutional forms has provided an enduring sustainable system, both socially and ecologically.

Contemporary studies on enduring commons and their communal governance institutions are beginning to provide some valuable principles for natural resource management. The likelihood of users designing successful common property institutions will be enhanced if the group is relatively small and stable; if it is relatively homogenous, with the members using similar technologies and having similar values and dis- 
count rates; if there is reciprocity and trust; and if the transaction costs for making and enforcing rules is low (Berkes \& Folke 1998, Ostrom 1990).

Common Property Resource (CPR) institutions have been successful in maintaining ecological capital as well as social fabric and rural communities. The elements contributing to this success and described by these recent authors would appear to confirm Ostrom's (1990) 8 characteristics of enduring, self-governing common property institutions:

1. Clearly defined boundaries. Individuals or households who have rights to withdraw resource units from the CPR (appropriators) must be clearly defined, as must the boundaries of the CPR itself.

2. Congruence between appropriation and provision rules and local conditions. Appropriation rules restricting time, place, technology, and/or quantity of resource units are related to local conditions and to provision rules requiring labour, material, and/or money.

3. Collective choice arrangements. Most individuals affected by the operational rules can participate in modifying the operational rules.

4. Monitoring. Monitors, who actively audit CPR conditions and appropriator behaviour, are accountable to the appropriators or are the appropriators.

5. Graduated sanctions. Appropriators of common property resources who violate operational rules are likely to have graduated sanctions imposed (depending on the seriousness and context of the offence) by other appropriators, by officials accountable to these appropriators, or by both.

6. Conflict resolution mechanisms. Appropriators and their officials have rapid access to low cost local arenas to resolve conflicts among appropriators or between appropriators and officials.

7. Recognition of rights to organise. The rights of appropriators to devise their own institutions (collective action) are not challenged by external governmental authorities, and for CPR's that are part of larger systems.

8. Nested enterprises. Appropriation, provision, monitoring, enforcement, conflict resolution, and governance activities are organised in multiple layers of nested enterprises.

Elinor Ostrom's additional characteristic of some successful common property arrangements, that of nesting of larger or more complex CPR systems, has been built on further in recent studies. CPRs nested in an ecological context at various scales is particularly important in the design of contemporary CPR arrangements and bioregional planning (e.g., McKean 1996, Brunckhorst et al. 1997). The bioregional and multipleuse contexts are particularly relevant to social-ecological nesting and social-institutional nesting of local to regional scale to National (or international) contexts and the relevance of Biosphere reserves as a legitimising framework between local collectives and (much larger) integrated, multi-functional, bioregional frameworks (Brunckhorst 2000).

Folke et al. (1998) also summarised principles drawn from case studies of linked social-ecological systems for building resilience and sustainability:

1. Using management practices based on local ecological knowledge.

2. Designing management systems that 'flow with nature'.

3. Developing local ecological knowledge for understanding cycles of natural and unpredictable events.

4. Enhancing social mechanisms for building resilience.

5. Promoting conditions for self-organisation and institutional learning.

6. Rediscovering adaptive management.

7. Developing values consistent with resilient and sustainable social-ecological systems.

Linked social-ecological systems, such as the enduring commons highlighted in Berkes \& Folke (1998), have developed the ability to respond to changes and to adapt in an active way because such adaptations were key to survival. Folke et al. distilled a list of social-ecological characteristics, practices and mechanisms important for sustainable, resilient systems. These highlighted management practices based on ecological context and principles of landscape ecology, for example:

- protection of habitat and sub-catchments;

- temporal restrictions on harvest; timed resource rotation;

- management of landscape patchiness;

- spatial resource allocation;

- response to ecological 'impulses' and 'surprises';

- nurture of renewal and/or succession; and,

- managing ecological processes at multiple scales.

In turn, these elements of ecological knowledge must be linked to methods of collective decision-making, monitoring and information transfer. This must include geographical and generational knowledge transfer, in addition to integration of knowledge with the roles of stewards, regulations and sanctions as they relate to resource management. There is now clear evidence that local-level institutions learn and develop the capability to respond to environmental feedbacks faster than do centralised agencies. Learning from local social-ecological systems and combining insights gained in adaptive management in western science may counteract many of the prevailing crises of conventional resource management (Brunckhorst 1998, Brunckhorst \& Coop 2000). In addition the nested hier- 
archy of community-based action and lessons from institutions with such enduring resilience might be applicable nested within the bioregions, which in turn are nested in ecoregions (see Brunckhorst 2000).

There remains an urgent need to design institutions that safeguard the dynamic capacity of ecological and resource production systems. Resource and ecosystem management is necessary but it requires fundamentally different approaches and facilitation of substantial transformation of many formal and informal institutions and organisational arrangements-not mere tinkering with current models and practices. One way of rethinking resource management social science will be through a focus on property rights institutions and in particular common-property systems. Modern, contemporary CPRs need to be developed as experimental models (see various authors in Hanna et al. 1996, McKean 1997, 2000). This is why the large body of case studies and theoretical/institutional studies are so valuable for insights into how to re-design currently detrimental institutions in novel ways (see Brunckhorst \& Mouat 2000, Coop \& Brunckhorst 2000).

\section{THE UNESCO BIOSPHERE RESERVE PROGRAM}

The seminal meeting for what would become the 'Man and the Biosphere' (MAB) biosphere reserve program was held at UNESCO House in Paris in 1968. The Biosphere Reserve program began in earnest with the first meeting of the MAB International Co-ordinating Council in 1971. The international network of biosphere reserves was proposed to protect the world's major biomes or ecological units. By the time the 'Minsk' Action Plan for Biosphere Reserves (UNESCO 1984) was produced, the program was already visionary, aiming to reconcile utilisation of natural resources with long-term protection through an interdisciplinary approach to sustaining nature and society (Batisse 1982, 1993, UNESCO 1984, 1995). Over 200 Biosphere Reserves had been nominated by 1984 . There are now more than 350 Biosphere Reserves in 100 participating nations. The international network also provided a unique set of sites and opportunities for long-term monitoring, research and communication into the ecological, social and economic aspects of conservation and sustainable development (see Appendix 1 for discussion of some misconceptions).

Biosphere Reserves are fundamentally concerned with whole-of-landscape processes, whether inside or outside of protected areas, across a variety of land tenures and uses. They aim to sustain the biodiversity and productive capacity on a regional scale that is appropriate to the ecological processes and human use and cultural identity with that landscape. Hence, they are vehicles for managing the social, cultural and institutional change and capacity-building at the multiple scales that is required to deal with the future sustenance of the biosphere and humanity.

The MAB program provides an enabling mechanism and multiple tool box to explore new methods for planning and practising sustainable resource management which is integrated with conservation activities. A Biosphere Reserve gives local communities new responsibilities for their own sustainable future while providing a thread to re-sew people's identity to the landscape. This contrasts with managing their own 'patch' in isolation and/or being excluded from ownership and responsibility for managing nearby public land in a wider context. The functions of biosphere reserves are implemented across a landscape region (bioregion) of different uses and environmental condition.

Major functions of the UNESCO Biosphere Reserve program were traditionally described as conservation, development and logistic support (research, monitoring, education \& training). These functions might be described as:

- conservation of biodiversity;

- increased ecological understanding; and,

- experimentation with, and demonstration of, ecologically sustainable development.

These are integrated through a multi-disciplined approach, focusing on 10 major objectives.

1. Local community participation, decision-making and responsibility.

2. Integrated resource planning and management.

3. In situ conservation and restoration.

4. Research.

5. Monitoring.

6. Regional planning \& development.

7. Environmental education \& training.

8. Ecologically sustainable development.

9. Information \& communication.

10. Developing an international network.

I hope it is becoming obvious how compatible and potentially synergistic these functions and objectives are with the principles and characteristics that have been distilled for successful CPR regimes briefly outlined above. Let us consider the spatial arrangements that are suggested by the Biosphere Reserve model, which are complimentary to CPR systems as well as Mike Scott's suggestions for integrated biodiversity conservation strategies.

In the 1984 Action Plan for biosphere reserves these functions became generalised for practical implementation and planning as 'core', 'buffer' and 'transition' zones (UNESCO 1984, 1995, Bridgewater 1994). While generally portrayed as a circular 'target' diagram, the concept refers to the need to manage land uses and 
functional ecological flows across an entire landscape mosaic which also includes a socio-economic dimension. The so-called 'core' areas are priority conservation areas (i.e., national park or IUCN category I or III) representing regional biodiversity and as monitoring or reference sites for adaptive management. 'Buffer' zones are really one end of a continuous transition region, extending further into an area of co-operation, where biodiversity-threatening influences on the core and the surrounding landscape are minimised (Batisse 1982, 1993, Brunckhorst \& Bridgewater 1996; see Fig. 1). In addition, biosphere reserves provide for increased community ownership and responsibility of protected areas as well as private lands, environmental restoration, monitoring and experimental ESD projects with public and private partners. A forth zone might therefore be termed a Zone of Co-operation.

Sustaining biological diversity will not be achieved in highly protected reserves, nor even along their boundaries. At last, perhaps, the debate is no longer based on viewing conservation reserves (large or small) from their border inwards; it is now focused outwards from the border and, indeed, on whether the borders should exist at all. Conservation reserves will still be important, but must become 'open' reserves in the broader landscape context. It is only by stretching out beyond, truly engaging with local communities in experimenting and demonstrating sustainable development and conservation that there will be any hope of maintaining what is contained within, together with the greater stakes, which occur beyond. The corebuffer-transition concept might be better envisaged as 'ripples on a pond' - conservation as an open system spreading out across a landscape building a sustainable future for people and maintaining ecological functions. This allows a nesting of local CPR arrangements to be developed as part of the sustainable land use components of buffer and transition areas; for example, forest woodlots collectively managed might contribute adequate buffer zones to the core, while a CPR regime for collective grazing around, but outside the buffer zone would be an appropriate transition zone. Several local CPR regimes/groups might collectively make management decisions about the whole Biosphere Reserve and include government resource management agencies as partners.
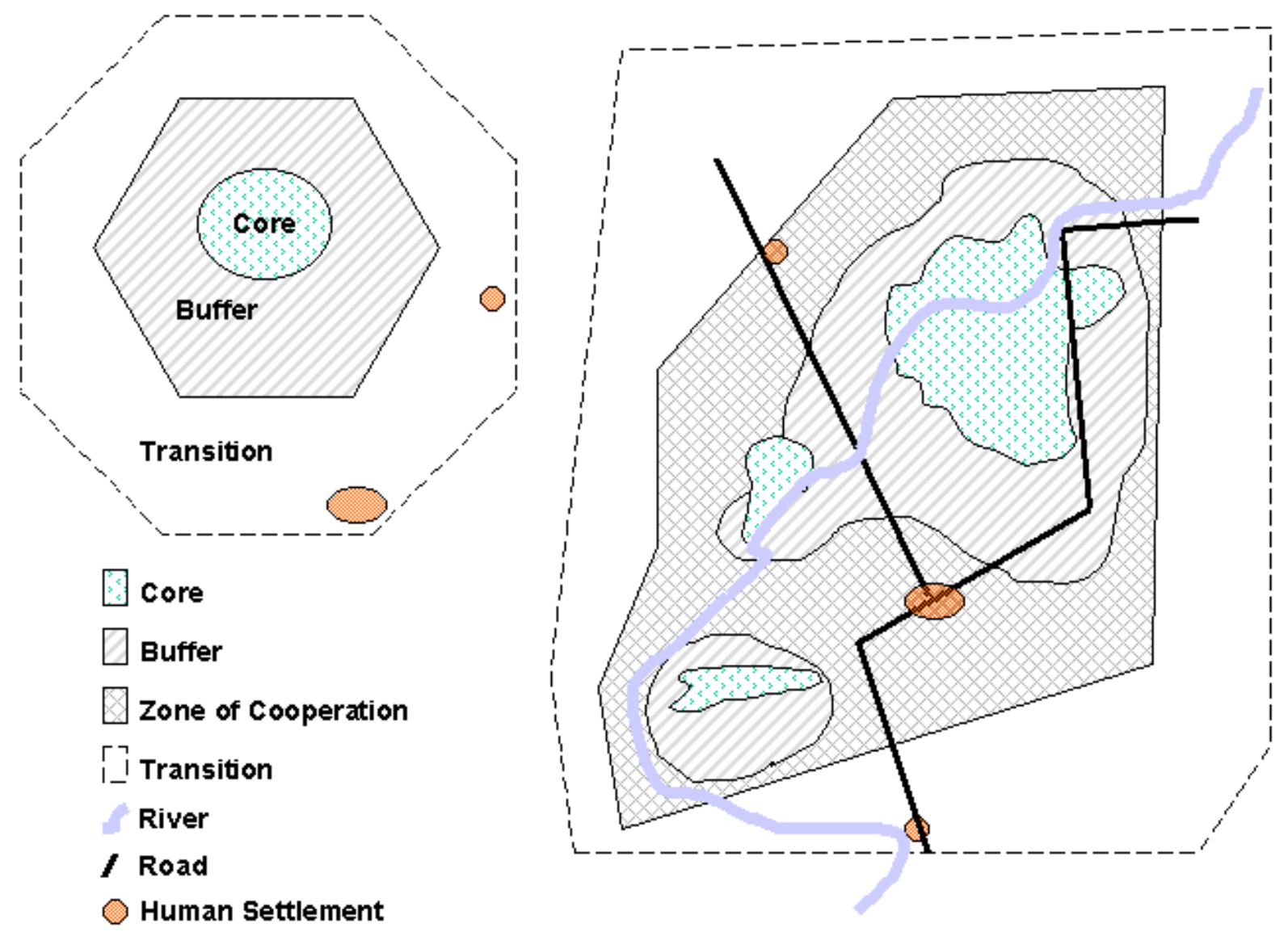

Fig. 1. Theoretical, concentric circles of Biosphere Reserve model (left) and application of model in practice (right). (From Brunckhorst 2000) 
People are an essential part of the fabric of landscapes. There is probably no ecosystem that remains unaffected in some way by human activity. Through the evolution of the Biosphere reserve program over the last 30 years, we have learned that they require multi-functional zones. Bioregional design for Biosphere Reserves are not arbitrary or purely jurisdictional, or concentric, but areas planned and spatially designed for environmental protection of different degrees, and also incorporating representative local ecosystems, the distribution of human populations and land uses. Reserves do not work unless they are designed to stimulate a cooperative response from local peoples, whose supportive work as reserve promoter-protectors turns out to be crucial to the biodiversity conservation component of biosphere reserves. To the extent that ecological protection goals can be combined with economic activities that support local populations, biosphere reserves themselves can be made larger and thus offer the possibility of extending planned habitat corridors or restoration, providing for more species diversity and improved resilience of local ecological processes and productive rural land uses, ultimately sustaining both natural and social capital. Therefore, people and their activities are considered a part of a biosphere reserve and should be encouraged in their participation and ownership of the program at several levels. This not only encourages greater acceptance and understanding of the need to conserve biodiversity but ensures the operation of the biosphere reserve at regional scales, to act as an agent of social transformation of attitudes and values towards common values for a sustainable future. What policy and practical mechanisms will allow a more integrated cross-jurisdictional mechanism for planning sustainable land use? Again this question needs to be attacked from several angles. The political, legal, organisational and institutional research on Common Pool Resources and successful Common Property Resource management regimes can provide some of the answers that need to be incorporated into the development of on-ground models.

One state-of-the-art model being developed by local communities in the Riverland in South Australia is Bookmark Biosphere Reserve. Operating at a regional landscape (bioregional) scale, it draws together community visions, values and actions dealing with a complex web of environmental and social challenges through a similarly complex network of multiple land tenures, public-private partnerships and resources, and multi-disciplinary professional capacities. The remainder of this paper will examine the creation of Bookmark Biosphere Reserve in South Australia, designed as an exemplar of the newest and most creative ways of combining the preservation of ecological habitat and processes with ecologically sustainable development and restorative industries for the human populations within and near the reserve.

\section{BOOKMARK BIOSPHERE RESERVE}

\section{Background}

Communities of South Australia, Victoria and New South Wales living along the Murray River are faced with a number of huge environmental challenges affecting their future. These include enormous rates of soil loss, landscape degradation and species loss. Together with the infusion of saline ground waters and decreasing water quality, along with disappearing wetlands - the liver and kidneys of the River-these processes are collectively threatening the sustainability of all Riverland communities.

Productivity of this mallee ecosystem is low. The region receives an average of $240 \mathrm{~mm}$ of annual rainfall with annual evaporation rates sometimes greater than $2300 \mathrm{~mm}$. Droughts are frequent and are punctuated with erratic floods. Soils are fragile and poor with deficiencies in structure and nitrogen content. The hydrology of the floodplain and wetlands of the Murray River has been altered by a variety of engineering projects designed to support agriculture and irrigation development. Problems of salinity within the ground water has been compounded by other factors including loss of deep rooted vegetation through land clearing for timber and pastoral throughout the past century. Many of the land degradation problems within the biosphere reserve are replicated on lands scattered throughout the drainage of the Murray River and its tributary, the Darling, which together drain one-seventh of the continent.

\section{A variety of partnerships}

Bookmark Biosphere Reserve constitutes now more than $7000 \mathrm{~km}^{2}$ (Fig. 2). It is made up of nine different types of land tenure including private land conservation reserves, game and forestry reserves, National Trust land and long-term pastoral leases. Some portions of land in the biosphere are the responsibility of the State government. The federal government nominally holds title to another portion. This is the Calperum pastoral lease $\left(2000 \mathrm{~km}^{2}\right)$ which was purchased with funds provided jointly by a Chicago benefactor and the federal government. Through a 'Deed-inTrust', Calperum became the collective responsibility of the local communities to manage deciding which 
parts will be totally protected, areas for ecological restoration and other parts for experimental development of novel industries for the future, which might also include other areas of the Biosphere Reserve. The Bookmark Biosphere Trust was inaugurated with local community membership to make joint decisions on use of Calperum, effectively as a Commons, and to contribute to 'futures' planning for the whole region- a huge challenge and responsibility. In joining this collective together, State and Federal governments have vested the community with the ownership and responsibility for selecting goals for management of this entire regional landscape.

The Riverland communities, through nominated representatives, manage the land within the Biosphere Reserve and accomplish required tasks through a citizens committee, the Bookmark Biosphere Trust. The community-based Trust is constituted under the South Australian National Parks Act. The Trust is the formal management body responsible for Bookmark Biosphere Reserve. State (Department of Environment \& Natural Resources), Federal (Environment Australia) and private sector professionals serve the trust in understanding and implementing management options.

The flood plains of Bookmark Biosphere Reserve are recognised as internationally significant wetlands for waterfowl and migratory species. Australia is a party to several international conventions for the protection of these areas (e.g., RAMSAR). The 'Calperum' Pastoral Lease which incorporates many of these wetlands of international significance is also the focal point for the community to experiment with novel sustainable industries. However, large-scale landscape recovery and species restoration are necessary and integral to the pursuit of ecologically sustainable development initiatives.

While there is strong bi-partisan political commitment to the future of Bookmark, governments do not have sufficient resources in the long term to recover degraded land and carry out the conservation programs that are the basis for the biological and cultural heritage of the Riverland. There are benefits to a lack of resources. If the community feels strongly about a particular course of action, it must share the responsibility for implementing it. In the process the Bookmark Trust comes to understand the program well, develops its own networks and capacity-building partners, and is able to market the program effectively throughout the broader community. This, in turn, increases community participation and publicprivate sector support. The Bookmark Biosphere Trust is an innovative and far sighted group of citizens concerned with the long-term sustainability of the natural environment, social values and standard of living in the Murray Riverland of South Australia. This is indeed a bold commitment to support a 'bottom-up' culture of capacity to accomplish conservation goals with few resources, political harmony, and new productive and innovative working relationships to leverage available resources, commitment and talent. This synergy, therefore, provides for combinatorial resource and capacity building from 'bottom-up' (community), 'top-down' (government) and 'sidewaysin' (private sector).

Such commitment is further demonstrated by the community and the private benefactor who helped with the purchase of Calperum Pastoral Lease. Most recently, Mr Brooks McCormick has contributed a further $\$ 2 \mathrm{M}$ to build an Environment Centre to ShowCase Bookmark Biosphere Reserve programs for innovative land management, conservation, ecologically sustainable development, environmental education and community participation. The Riverland community provided the concept for an Environment Centre assisted by the pro bono services of several professionals. The town of Renmark has donated a site for the Centre and will provide service connections.

\section{Sustainability in a low productivity landscape?}

The main sources of income in the mallee Riverland are pastoral development and horticultural crops. Pastoralism is not economically viable in the dry rangelands when international wool prices are low. It would also seem ecologically unsustainable during times of drought. Cropping and agriculture is based on the provision of irrigation water from the Murray river. During dry periods, the salinity of the river water is nearing the tolerance limit for citrus, the major crop. Therefore, in addition to land recovery new enterprises for sustainable production will be required to support Riverland communities in the future (see also Fitzhardinge 1994, Freudenberger \& Freudenberger 1994, Landsberg et al. 1995).

To support land management programs the Bookmark Biosphere Trust is faced with the creative challenge of experimenting with and establishing a suite of novel resource uses compatible with conservation and land recovery. With the support of the Williamson Fellows, a group of citizens grappled with the meaning of ESD to the Riverland. They considered a range of social justice and environmental principles and came up with a provisional list of industries. This left the Bookmark Trust, assisted by its public \& private sector partners, with the task of working through the ramifications of developing experimental applications of ESD in the real world-for which there are very few examples to draw upon. 


\section{BOOKMARK BIOSPHERE RESERVE}

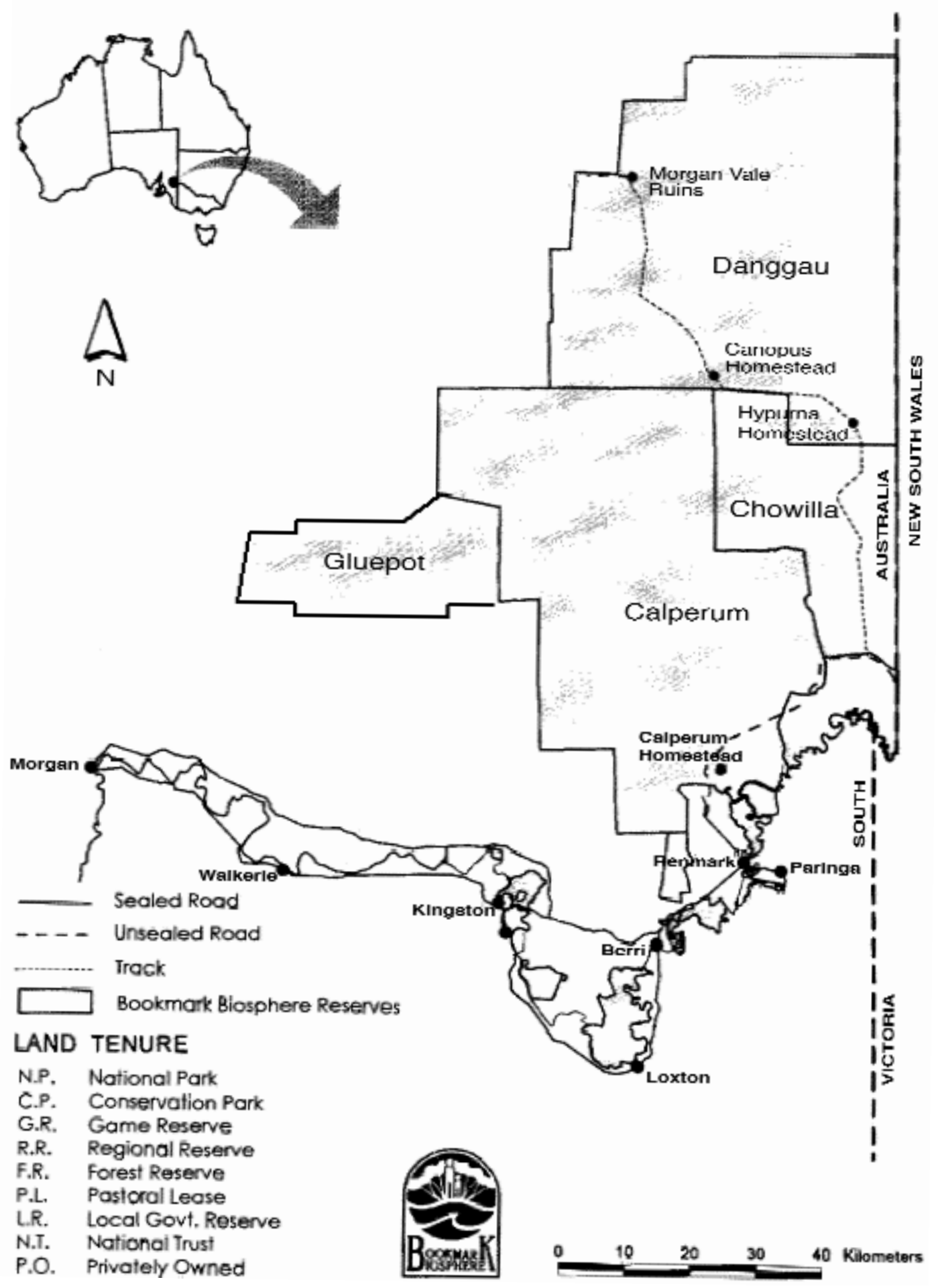

Fig 2. Bookmark Biosphere Reserve (South Australia), in the Mallee Riverland bioregion part of the lower Murray-Darling ecoregion 
This is complex enough, but is compounded by the limitations of a low productivity system, existing environmental debt, water quality issues, employment and training needs, and economic feasibility. While several potential ESD activities were considered, two, ecotourism and diversified animal products, were chosen for initial trials.

The diversified animal products processing operation is based on the possibility of utilising resources that will decrease pressure on plant and aquatic communities to aid environmental recovery while providing some socio-economic benefit.

Feral goats (numbering in excess of 15000 in the past 2 years) damage vegetation on the biosphere reserve. The goats are costly to remove, but could generate money if the meat and leather could be sold. Eradication is impossible and would not be economic anyway (Freudenberger 1993). However, if partial eradication caused goat numbers to fall below a density that was economically viable to remove, harvest would become uneconomical and population numbers would rise again within a few months.

Australia's 2 largest species of kangaroo also occur in large populations in this altered pastoral landscape, reaching densities in excess of $25 \mathrm{~km}^{-2}$. Unnaturally high kangaroo (and feral goat) populations have developed because of land clearing and development of watering points for sheep grazing. A diversified meat processing industry, combining sustainable kangaroo harvesting and goat removal might maintain a steady supply of meat to a local abattoir and provide a few jobs (see Caughley et al. 1987).

If ESD means that the allowable annual harvest is only the nitrogen and energy fixed by the system in a given year, such a low productivity landscape may not generate enough goats and roos within the biosphere reserve to meet western economic requirements for investment return, and cover costs of interest repayments, depreciation of equipment, insurance, holiday pay etc. Highly productive landscapes are more capable of meeting the needs of investor economics.

However, 4 other factors may contribute to socio-economic viability. Firstly, if nitrogen and energy fixed in that landscape are used directly by people living in or around the biosphere, the landscape might support the activity as an ESD. Secondly, the resource pool of goats and kangaroos actually emanates from the biosphere reserve and beyond (a small change in South Australian law has allowed goats to be considered in this way). Hence low productivity is partly compensated by expanding the scale or area from which resources are harvested. Thirdly, if the industry is further augmented with bone discarded by local butchers, and carp are also harvested, a variety of prime cuts, pet food, fish meal, leathers, small goods and blood and bone fertiliser can be produced out of a single facility. Most of these items have existing or developing market opportunities.

A second ESD industry now in development and early implementation stages is native floriculture-initial planting is expected in August/September following the frosts. Transformation of a degraded area by the Calperum shearing sheds to a fenced and serviced floricultural facility is largely due to the efforts of Roger Fielke, who comes to the project with the experience of growing native bush foods for the Red Ochre Grill Restaurant. Seedlings and cuttings have been propagated by the floriculture professional team in Melbourne from samples and seed gathered across the Bookmark region. Local experts and researchers from Adelaide University and the Adelaide Botanic Gardens have identified more plants in subsequent surveys.

\section{Nested CPRs within the greater Bookmark whole}

Calperum can be interpreted as consistent with a Common Property arrangement managed through collective decision making and matching many of the principles we now know reflect such systems - though I admit I was unaware of these when I was involved in initiating and facilitating its development with local people and communities. As the total area and complexity of the Bookmark Biosphere project has expanded enormously in a relatively few years, a number of 'Landcare' groups were established to spread the share of land management responsibility and decision making. This is a unique organisational arrangement for Landcare groups. Each is responsible for an adjoining area of land and effectively a 'branch' CPR sitting under the Bookmark Biosphere Trust, which integrates planning and decisions across Landcare groups and the rest of Bookmark. Hence, this might be interpreted as a group of adjacent CPRs nesting under the greater whole CPR which is Calperum, which in turn is part of the multi-functional whole that makes up the Bookmark Biosphere Reserve project and includes other public and private partners. Perhaps, the next challenge before the local communities and their partners is to more fully understand, and learn to communicate the holistic values for environmental health alternative land uses, social values such as community cohesion, training, jobs and local industries that help recover environmental debt-reducing disturbance and grazing pressure by animals which are paying for their own removal, thereby contributing to restoration of social capital, natural capital and financial capital. Innovative holistic consideration of a wide variety of individual components can be brought together nurturing and restoring social, natural, human, financial and physical capital to deliver a whole that is certainly greater than the sum of the parts! 


\section{ASSEMBLING NEW MODELS}

I have left a few loose ends. This might be due to some oversight but is also deliberate. I hope readers will see the synergies, linkages and potential of drawing together a variety of different characteristics and principles that we have all learnt from research and practical application of Bioregional Planning, CPR management institutions and the UNESCO Biosphere Reserve program. I hope a variety of readers-community, professionals, planners, policy makers and managers - will be able to identify and communicate various other useful elements or synergies that might be incorporated in building novel future models out of various private and publiparcels of land and sea, and institutional arrangements and capacities. This does raise the issue of integrating

our policies and planning at even broader scales, in that we need a working framework that might be useful in understanding and planning the multi-scale nesting of contemporary CPR arrangements (in designing New Commons) within broader collective decision making, multi-functional resource management systems (a Biosphere Reserve?), which in turn, probably nest in a broader cultural landscape region (Bioregion). These socially and ecologically defined bioregions nest within Ecoregions at continental scales (Brunckhorst 2000).

Well-managed risks need to be taken if we are to advance novel solutions for the next millennium. We need to build and develop a range of models such as the Bookmark project relevant to their own context social, ecological, land or sea use production, institutional, organisational and political. Other kinds of CPRs, Biosphere Reserve designs and Bioregional models need to be experimentally developed. Critical foci not only in Australia, but globally should be the semi-arid rangelands and the land-sea interface.

Acknowledgements. My thanks to Michael Archer, Margaret McKean, Peter Bridgewater, Margaret Herring, Bill Rutherford, Richard Thackway, Phil Coop, Mike Harper, Mike Kidman, Pamela Parker, Pat Feilman, George Rabb, for stimulating my thoughts on these issues and synergies. The 'on-ground' authors of the second part of this story and their own future are the communities of the South Australian Riverland and the Bookmark Biosphere Trust. I also record sincere thanks to the Brooks McCormick, and the Williamson, Myers and Potter foundations, and all individual partners for their commitment to sustaining all forms of capital.

Appendix 1.

Problems in perceptions of biosphere reserve-Some brief comments

The concepts and principles of the MAB program were well ahead of their time. Implementation was hampered by the depauperate position of UNESCO internationally in the early 1980s and, by greater attention being given to more charismatic programs such as World Heritage. In retrospect, it would seem that a complex and innovative idea such as biosphere reserves at a time prior to the Brundtland report (WCED 1987) and before preparations for the UNCED 'Rio' Conference was difficult to enunciate and very hard to 'sell' to science and policy sectors, let alone more generally.

Another hurdle for the program was created in its first decade. Most countries with federal systems of government and many other nations, simply nominated to UNESCO their 'special' national parks as biosphere reserves. Accordingly, Australia has 12 biosphere reserves, nominated originally for their high conservation value and for research opportunities. Consequently, most of these have been operational at only one of the functional levels of a biosphere reserve, that corresponding to a 'core' area (i.e., a national park or conservation reserve can only be a core area, although there may be a network of core areas throughout a biosphere reserve). Until recently, all were public lands alone, from which most local people felt excluded. The broad organisational framework required for practical implementation has also been lacking.

This has exacerbated mis-conceptions and hampered implementation, particularly in Australia and the USA. On one hand, extreme green groups have claimed that biosphere reserve status reduced protection to a national park making it 'multiple-use'. Conversely, some industry sectors were concerned that access over large areas would be restricted. Neither is true.
Some extreme right-wing groups have pushed US Senate inquiries to view the program as if the UN was threatening Nation State sovereignty - a quite ridiculous assertion, but unfortunately to the demise of the US MAB program.

Today, there is much greater understanding of ecologically sustainable development and the need for integration and management at the scale of regional landscape ecosystems $(10 \mathrm{~s}-100 \mathrm{~s} \mathrm{~km})$. Support and interest for the UNESCO MAB program is also growing. The increasing credibility and potential of the biosphere reserve network is now recognised in planning the main logistic base and future activities in response to the UNCED process - especially with respect to the 'on-ground' implementation of Agenda 21 which needed to verify its postulates in several areas and chose the MAB program to do so. A valuable, if not crucial, attribute of the biosphere reserve concept is its flexibility and adaptability to a variety of situations that allows it to be interpreted locally and to gather a broader influence through time. A further advantage of the program is the lack of rigid regulations, it has no legally binding status (it is not tied to an International Convention) and is no threat to land holders, rural communities or industry sectors; it encourages and supports those who wish to pursue common values and principles for sustainability. However, it contributes legitimacy, credibility and profile that provide a 'justifiable' means to build social cohesion at neighbour/landholder and local community levels. At another level, it again legitimises and facilitates social cohesion between public and private partners, townships, and local governments, which provides a means of nesting various levels of 'wholes' and collective decision-making against 'holistic' goals. 


\section{LITERATURE CITED}

Batisse M. 1982. The Biosphere Reserve: A Tool for Environment Conservation and Management. Environmental Conservation 9(2): 101-111

Batisse M. 1993. The Silver Jubilee of MAB and its Revival. Environmental Conservation 20(2): 107-112

Berkes, F. \& C. Folke (eds). 1998. Linking Social and Ecological Systems; Management Practices and Social Mechanisms for Building Resilience. New York: Cambridge University Press

Bridgewater P. 1994. Conservation strategy and research in Australia - how to arrive at the 21st century in good shape, pp. 17-25 in, Conservation Biology in Australia and Oceania (C.Moritz \& J. Kikkawa, eds). Surrey Beatty \& Sons, Chipping Norton

Brunckhorst D.J. 1992. Biodiversity: The Contribution of Community-Based Programs. House of Representatives Standing Committee on Environment, Recreation and the Arts. Inquiry report to the Parliament of the Commonwealth of Australia. AGPS, Canberra. 98 pp. ISBN 0644 921713

Brunckhorst D.J. 1993. Biodiversity: The Role of Protected Areas. House of Representatives Standing Committee on Environment, Recreation and the Arts. Inquiry report to the Parliament of the Commonwealth of Australia. AGPS, Canberra. 97 pp. ISBN 0644286687

Brunckhorst, D.J. 1994. Protected Area Buzzwords - An Attempt to Define some Current Terminology in a more Meaningful Way. Pp.35-37 in Brunckhorst, D.J. (ed.) Marine Protected Areas and Biosphere Reserves: 'Towards a New Paradigm' Proceedings of the 1st International Workshop on Marine and Coastal protected Areas, Canberra, Australia, August 1994. ANCA/UNESCO

Brunckhorst, D.J., 1995. Sustaining Nature and Society - A Bioregional Approach. Inhabit 3: 5-9

Brunckhorst, D.J. 1998. Creating Institutions to Ensure Sustainable Use of Resources. Habitat International 22 (4): 347-354

Brunckhorst D.J. 2000. Bioregional Planning: Resource Management Beyond the New Millenium. Harwood Academic: Gordon \& Breach, Amsterdam. ISBN 90-5823-046-5

Brunckhorst D.J. 2000. Synergies for Social, Ecological and Economic Recovery on Newly Created Commons. In, N. Dolsak \& E. Ostrom (Eds), Constituting the Commons: Crafting Sustainable Commons in the New Millennium. Proceedings of the $8^{\text {th }}$ Biennial Conference of the International Association for the Study of Common Property. University of Indiana, Bloomington, Indiana

Brunckhorst D.J. 2000. Introducing Landscape Futures. Chapter 1, in Landscape Futures, D. Brunckhorst \& D. Mouat (eds). Proceedings of the International Symposium on Landscape Futures (Refereed proceedings of international symposium, Sept. 1999) UNESCO Institute for Bioregional Resource Management and University of New England ISSN 1443-7643 ISBN 1863896643

Brunckhorst D.J. \& P. Bridgewater. 1996. Identifying Core Reserve Networks in Coastal Bioregions: A Novel Implementation Framework for Coastal Marine Biosphere Reserves. Proceedings of 2nd UNESCO International Conference on Biosphere Reserves, Seville, Spain, 20-25 March 1995

Brunckhorst D.J., P. Bridgewater \& P. Parker. 1997. The UNESCO Biosphere Reserve program comes of age: Learning by doing, landscape models for a sustainable conservation and resource. Pp. 176-182 in, P. Hale \& D. Lamb (eds), Conservation Outside Reserves. Centre for
Conservation Biology: UQ, Brisbane. ISBN 0867767286

Brunckhorst, D.J., P. Coyne, I. Cresswell \& R. Thackway. 1998 Australian Protected Areas - Toward a Representative System. Journal of the Natural Areas Association 18(3): 255-261

Brunckhorst, D.J. and N.M. Rollings. 1999. Linking Ecological and Social Functions of Landscapes: I. Influencing Resource Governance. Journal of the Natural Areas Association 19(1): 34-41

Brunckhorst D..J \& Mouat, D. Editors, 2000. Proceedings of the International Symposium on Landscape Futures (Refereed proceedings of international symposium, Sept. 1999) UNESCO Institute for Bioregional Resource Management and University of New England ISSN 1443-7643 ISBN 1863896643

Brunckhorst D.J. \& Coop, P., 2000. Social Eco-Logics Shape the Context of Future Landscape Management. Chapter 5, in Landscape Futures. D.Brunckhorst \& D Mouat (eds), Proceedings of the International Symposium on Landscape Futures (Refereed proceedings of international symposium, Sept. 1999) UNESCO Institute for Bioregional Resource Management and University of New England ISSN 1443-7643 ISBN 1863896643

Caughley, G., N. Shephard \& J. Short (eds) 1987. Kangaroos: their ecology and management in the sheep rangelands of Australia. Cambridge University Press

Coop, P \& D.J. Brunckhorst (2000). Creating Contemporary Commons to Enhance Economic Productivity: A Grazing Commons in Rural Australia. In, N. Dolsak \& E. Ostrom (Eds), Constituting the Commons: Crafting Sustainable Commons in the New Millennium. Proceedings of the $8^{\text {th }}$ Biennial Conference of the International Association for the Study of Common Property. University of Indiana, Bloomington, Indiana

Costanza R, d'Arge R, de Groot R, Farber S, Grasso M, Hannon B, Limburg K, Naeem S, O'Neil R V, Parvelo J, Raskin R G, Sutton P and van den Belt M. 1997. The value of the world's ecosystem services and natural capital. Nature 387, 253-260

Daily G (ed). 1997. Nature's Services: Societal Dependence on Natural Ecosystems. Island Press, Washington DC

Edwards, V.M., and N.A. Steins. 1999. Developing an Analytical Framework for Multiple-Use Commons. Journal of Theoretical Politics 10(3): 347-383

Edwards, V.M., and N.A. Steins. 1998. A Framework for Analysing Contextual Factors in Common Pool Resource Research. Journal of Environmental Policy \& Planning 1: 205-221

ESD Strategy, 1992. National Strategy for Ecologically Sustainable Development December, 1992. Australian Government Publishing Service. $128 \mathrm{pp}$

Fitzhardinge G. 1994. An alternative understanding of the relationship between the ecosystem and the social system: Implications for land management in semi-arid Australia. Rangelands Journal 16(2): 254-264

Folke, C., Berkes, F, \& Colding, J. 1998. Ecological practices and social mechanisms for building resilience and sustainability. In F. Berkes \& C. Folke (eds). Linking Social and Ecological Systems; Management Practices and Social Mechanisms for Building Resilience. New York: Cambridge University Press

Freudenberger D.O. \& C.D. Freudenberger. 1994. Good relationships: Ethical and ecological perspectives on rangeland management. Rangelands Journal 16(2): 321-332

Freudenberger D.O. (ed.) 1993. Proceedings of National Feral Goat Workshop. Bureau of Resource Sciences: Canberra

Gunderson, L., C.S. Holling and S. Light (eds), 1995. Barriers 
and Bridges to the Renewal of Ecosystems and Institutions. New York: Columbia University Press

Hansen A.J. \& F. di Castri (eds) 1992. Landscape Boundaries: Consequences for Biotic Diversity and Ecological Flows. Springer-Verlag, New York, Berlin. 439 pp

Hawken P. 1993. The Ecology of Commerce: How business can save the planet. London: Weidenfeld and Nicolson

HoRSCERA 1992. Biodiversity: The Contribution of Community-Based Programs. (D.J. Brunckhorst, ed.) Inquiry report of the House of Representatives Standing Committee on Environment, Recreation and the Arts, Parliament of the Commonwealth of Australia. AGPS, Canberra. 98 pp

HoRSCERA 1993. Biodiversity: The Role of Protected Areas. (D.J. Brunckhorst, ed.) Inquiry report of the House of Representatives Standing Committee on Environment, Recreation and the Arts, Parliament of the Commonwealth of Australia. AGPS, Canberra. $98 \mathrm{pp}$

Ishwaran N. 1992. Biodiversity, Protected Areas and Sustainable Development. Nature \& Resources 28(1): 18-25

IUCN 1993. Parks for Life. Report of the IVth World Congress on National Parks and Protected Areas. IUCN, Gland, Switzerland. $260 \mathrm{pp}$

Kellert S.R. 1986. Public Understanding and Appreciation of the Biosphere Reserve Concept. Environmental Conservation 13(2): 101-105

Landsberg J., C. James \& S. Morton, 1995. Integrating Grazing \& Biodiversity Conservation in Australia's Rangelands. Trees and Natural Resources, September 1995: 6-10

McKean, M. 2000. Designing New Common Property Regimes for New Landscape Futures. Chapter 7, in Landscape Futures, D.Brunckhorst \& D Mouat (eds). Publ., UNESCO/IBRM/UNE ISSN 1443-7643 ISBN 1863896643

McKean, M. 1997. Common property Regimes: Moving from inside to outside. In B. J. McCay and B. Jones (eds), Proceedings of the Workshop on Future Directions for Common Property Theory and Research. New Brunswick, N.J.: Rutgers University; URL, http://www.indiana. edu/ iascp/webdoc.html

Norton B.G. \& R.E. Ulanowicz 1992. Scale and Biodiversity Policy: A Hierachical Approach. Ambio 21(3): 244-249

Noss R.F. 1983. A Regional Landscape Approach to Maintain Diversity. Bioscience 33(11): 700-706

Noss R.F. 1993. A Conservation Plan for the Oregon Coast Range: Some Preliminary Suggestions. Natural Areas Association Journal 13(4): 276-290

Odum W.E. 1982. Environmental degradation and the tyranny of small decisions. BioScience 32: 728-729

Ostrom, E. 1990. Governing the Commons; The Evolution of

Editorial responsibility: Mike Archer,

Sydney, Australia
Institutions for Collective Action. Cambridge University Press. USA

Parker P. 1993. Australia's Biosphere Reserves: A Report. Australian National Commission for UNESCO and Australian Nature Conservation Agency. Canberra. 59 pp

Pretty J N. 1995. Regenerating Agriculture: Policies and Practice for Sustainability and Self-Reliance. Earthscan Publications, London; National Academy Press, Washington DC; ActionAid, Bangalore

Pretty J N. 1998. The Living Land: Agriculture, Food Systems and Community Regeneration in Rural Europe. Earthscan Publications Ltd, London

Reid T.S. \& D.D. Murphy. 1995. Providing a Regional Context for Local Conservation Action: A natural community conservation plan for the southern California coastal sage scrub. BioScience Supplement 1995: 84-90

Saunders D.A. 1990. The Landscape Approach to Conservation: Community involvement, the only Practical Solution. Australian Zoologist 26(2): 49-53

Slocombe D.S. 1993. Implementing Ecosystem-based Management: Development of theory, practice and research for planning and managing a region. BioScience 43(9): 612-622

Shannon, M.A., 1998. Understanding Social organizations and Institutions. Pp. 529-551 in, R.J. Naiman and R.E. Bilby (eds), River Ecology and Management: Lessons from the Pacific Coastal Ecoregion. New York: Springer Verlag

Thackway, R, D. A. Mouat \& D. J. Brunckhorst (2000). Introduction to Alternative Futures Workshop Analysis. Chapter 16, in Landscape Futures, D.Brunckhorst \& D Mouat (eds). Proceedings of the International Symposium on Landscape Futures (Refereed proceedings of international symposium, Sept. 1999) UNESCO Institute for Bioregional Resource Management and University of New England ISSN 1443-7643 ISBN 1863896643

UNESCO 1984. Action Plan for Biosphere Reserves. Nature and Resources 20(4): 1-12

UNESCO 1995. The Seville Strategy for Biosphere Reserves. Strategy developed by the 2nd Global Conference of experts on the UNESCO Biosphere Reserve Program, Seville, Spain, March, 1995. UNESCO, Paris. 18pp

Urban D.L., R.V. O'Neill \& H.H. Shugart, Jr. 1987. Landscape Ecology: A hierarchical perspective can help scientists understand spatial patterns. BioScience 37(2): 119-127

World Commission on Environment and Development (WCED) 1987. Our Common Future. Oxford University Press

Accepted by editor: January 26, 2001

Published on the Web: February 01, 2001 